of electoral reform, but the real need is for some of the checks and balances that would give those elected, by whatever means, power to moderate what governments propose.

\section{American free trade}

The North American Free Trade Agreement deserves better than the back-burner until the US election.

It is a shame that one of the casualties of the industrial world's almost general election fever is that the US Administration seems, at least for the time being, to have put on ice the North American Free Trade Agreement, the plan to extend the benefits of the 1990 free trade agreement with Canada to Mexico as well. Although the negotiations are believed to be well advanced, Mr Brian Mulroney, the Canadian Prime Minister, said at the weekend that he did not expect the deal finally to be struck until the "end of the year", which means after the US election.

The difficulty seems to be that this election campaign is not the best background for a trade deal; voters worried about jobs are not convinced that free trade is not a zerosum game, and the administration reflects that. Even the bilateral agreement with Canada is in trouble, with corrosive complaints that Canadian lumber is too cheap (because of arrangements for financing the cost of removing dead tree-stumps) and that some Japanese cars manufactured in Canada do not satisfy the requirement that half their value should derive from North America (even though the engine blocks are actually cast in the United States, and imported from there). The extension of the agreement to include Mexico, even with reservations about the speed at which tariffs would disappear, has raised more worrying hackles in the United States. Some say it is a way of exporting jobs south of the border, others that it is a device for exporting pollution (to a place where regulatory standards are less cramping).

Inevitably, arguments such as these, whether soundly based or not, are readily amplified in election years. Meanwhile, the economic benefits likely to be won by the United States itself from a larger market are admittedly more distant and therefore seem less tangible. But there are political and cultural benefits as well, not the least of them deriving from Mexico's potential role as a bridge between the United States and the still imperfectly comprehended territory further south. It is understandable that President George Bush should, for the time being, let the hustings make the conclusion of an agreement seem less urgent, but is it forgivable?

\section{Retroviral Michelangelo}

What will epidemiologists make of the scare that the world's hard discs would be wiped clean last Friday?

MiChelangelo's 517th birthday has come and gone without bringing computer-dependent parts of the world to a halt. Although the hard discs of personal computers at various scattered locations were wiped free of data by the computer virus designed to become active on that day, most machines appear to have survived intact. Epidemiologists will probably find that actual outbreaks of computer disease are too few and far between to be informative in the technical sense. Certainly there is only a small chance that the origin of this well-publicized outbreak can be identified from what is known of the incidence of outbreaks last Friday.

Luckily, some of the imponderables that usually have epidemiologists scratching their heads when confronted with a novel infection will not on this occasion be impediments to understanding. For example, the sections of the personal computer population at risk from infection are known in advance: computer viruses subvert a computer's operating system just as a real virus subverts the genetic apparatus of a cell, so that the feasibility of successful infection is, for the time being, necessarily specific to computers with the vulnerable system. (It may be different when 'open' systems, allowing intercommunication between computers, are a reality.) Similarly, the mechanism of transmission is not, in this case, in doubt: hard discs are infected by corrupted floppy discs, and then themselves generate infected floppy discs (verifying Koch's postulate).

It is also relevant that the Michelangelo virus resembles a retroviral infection, say by HIV. It could hardly be otherwise. Computer viruses corrupting hard discs the instant they infect them would not get very far in the world. This is why quickly lethal virus infection, as Marburg virus or that responsible for Lassa fever, are not such serious public health problems as, say, that for measles. The designers of Michelangelo were clearly aware that their virus should have a long latency period, allowing plenty of opportunity for cryptic replication as pro-virus rather than as virus proper. On this occasion, the long latency and also the advance warning allowing computer users to take simple prophylactic measures (such as resetting system dates) will also impede attempts to track down the focus of infection.

By now, the whole world knows what kinds of people are likely to be responsible. They are teenage computer enthusiasts who, a few years ago, were busily hacking their way into the Pentagon's databases, but who have now seized new opportunities for causing global chaos. From time to time, some of them are caught by the police and given suspended jail sentences. But before all innocent teenagers smart enough to use assembly language are picked up for questioning, it would be wise to remember that the Michelangelo virus is the best thing ever to have happened to software manufacturers seeking to protect their copyrights. The past week's fuss has also been a shot in the arm for those who sell software designed to neutralize known computer viruses. The real culprit may be a grown-up. 